\title{
Ocular involvement in sinus histiocytosis with massive lymphadenopathy
}

\author{
ZEYNEL A KARCIOGLU,' BELU ALLAM,' AND MICHAEL S INSLER² \\ 'From the Departments of Ophthalmology, 'Tulane University Medical School, and 'Louisiana State \\ University, School of Medicine, USA
}

SUMMARY Sinus histiocytosis with massive lymphadenopathy is a distinct clinical entity, with ophthalmic involvement in $10 \%$ of patients. Orbital as well as eyelid lesions have been described as part of the extra-lymph node involvement of this disorder. We recently examined a young boy with sinus histiocytosis with a bulbar conjunctival mass and chronic dacryocystitis.

Sinus histiocytosis with massive lymphadenopathy (SHML) is a disease of childhood and adolescence of unknown aetiology. ${ }^{2}$ It affects blacks more often than whites and has a self-limited course. The manifestations of sinus histiocytosis include lymphadenopathy with fever, leucocytosis, anaemia, raised erythrocyte sedimentation rate (ESR), and hypergammaglobulinaemia. ${ }^{34}$ Ocular lesions have been described in the orbit, eyelids, and uveal tract. ${ }^{56}$

We report a case of sinus histiocytosis with involvement of the conjunctiva and lower lid of the left eye and bilateral chronic dacryocystitis.

\section{Case report}

A 15-year-old black male from Honduras, small for his age, presented with non-tender, non-fixed submental and axillary lymphadenopathy, and an upper lobe opacity in the left lung. The right leg and scrotum had painless, non-pitting oedema with dry skin and soft, non-tender cutaneous nodules (Fig. 1). The testes were small.

The best corrected visual acuities were $20 / 20$, and intraocular pressures were normal in both eyes. Both lacrimal sacs were distended, and pressure over them resulted in a reflux of a yellowish purulent discharge. A $10 \times 8 \mathrm{~mm}$ nodule was present on the medial aspect of the left lower eyelid. This lesion was not tender, freely moveable, and was not related to the lacrimal drainage apparatus. On the medial aspect of the left bulbar conjunctiva an isolated, $5 \times 5 \mathrm{~mm}$, oval, pinkish nodule, partly covered with prominent blood Correspondence to Zeynel A Karcioglu, MD, O'Brien Ocular Pathology Laboratory, Department of Ophthalmology, 1430 Tulane Avenue, New Orleans, LA 70112, USA.

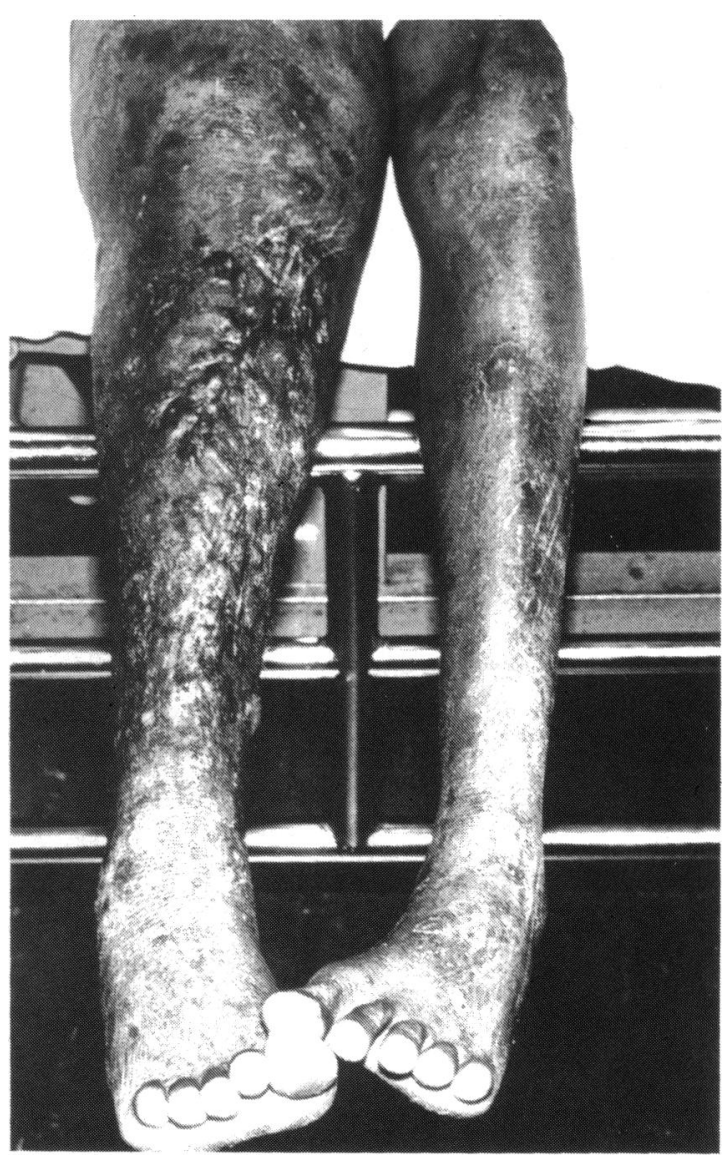

Fig. 1 The right leg with marked oedema and cutaneous nodules, particularly located in the lowerleg. 


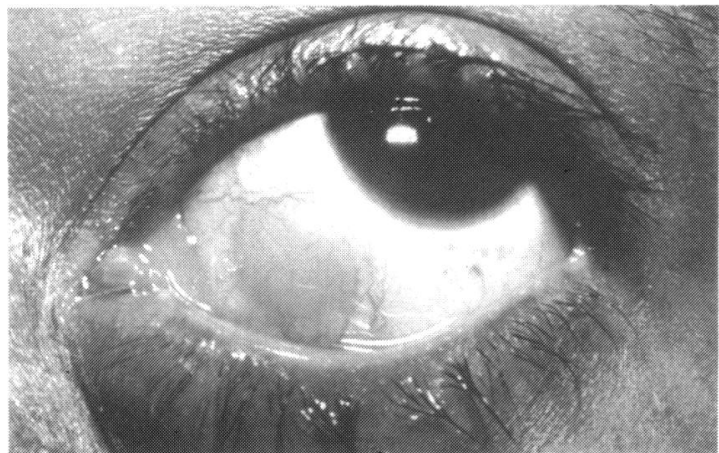

Fig. 2 The left eye with eyelid and conjunctival nodules.

vessels was observed (Fig. 2). This nodule was fixed to the underlying sclera. The neuro-ophthalmological and funduscopic examinations were within normal limits.

Laboratory and radiological examinations to rule out an infectious cause and/or some tropical disease related to the lymphadenopathy gave negative results. The ESR was $71 \mathrm{~mm} / \mathrm{h}$. The patient was severely anaemic with a packed cell volume (haematocrit) of $26 \cdot 7 \%$. The results of immunological investigation were consistent with primary immune deficiency. A CT scan of the orbits and sinuses revealed a left ethmoidal mass.

The lymph node biopsy from the left axillary region showed reactive lymphoid hyperplasia with distended sinuses containing a mixed population of cells including histiocytes, lymphocytes, plasma cells, and red cells. The predominating cell type, however, in the sinuses and in the medulla was histiocytes. Additional tissues obtained from the conjunctival nodule and ethmoidal sinus showed the same histology of a mixed infiltrate composed of histiocytes, lymphocytes with occasional plasma cells, and polymorphonuclear leucocytes. The predominating cell type in these biopsies was also the histiocyte, showing great morphological variation and phagocytic properties. These cells were large and irregularly shaped, with abundant, sometimes vacuolated cytoplasms and one or several oval nuclei and prominent nucleoli. The cytoplasmic vacuoles contained phagocytosed red cells, lymphocytes, and irregular proteinaceous deposits which were presumed to be cellular debris (Fig. 3). Mitotic figures were very rare. Immunoperoxidase stain for epithelial membrane antigen (EMA) was negative.

Lacrimal probing was performed and silicone tubes were placed into the nasolacrimal drainage system bilaterally. This procedure, in addition to systemic antibiotic treatment, resulted in a marked improvement of the dacryocystitis. The patient's general condition improved in four months with symptomatic support, and he left the hospital to return to his native country.
Fig. 3. The histological appearance of the conjunctival nodule with histiocytic infiltrate. The cells have vesicular nuclei with prominent nucleoli and abundant eosinophilic cytoplasm.

Phagocytosed red cell fragments and proteinaceous deposits are identified in some hystiocytes (arrow). Hand E; main photograph $\times 250$; inset $\times 1000$.

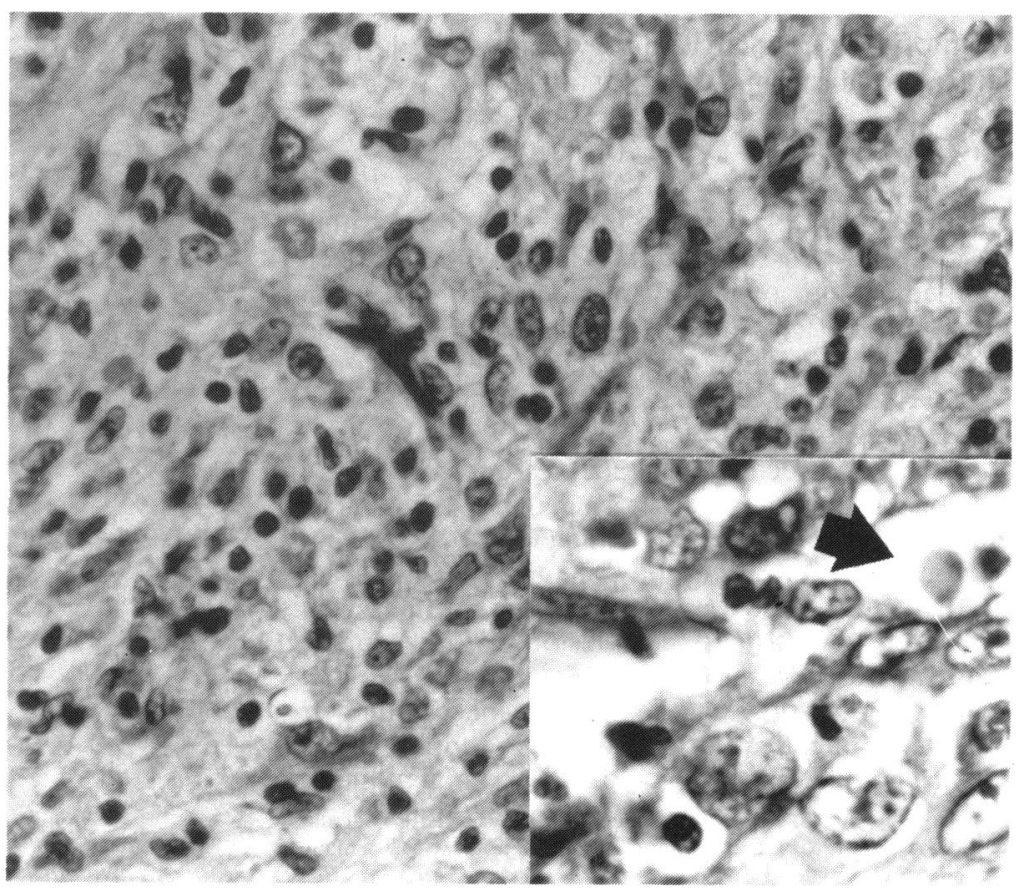




\section{Discussion}

Sinus histiocytosis is generally a benign, nonneoplastic condition characterised by massive lymphadenopathy. Cervical adenopathy is most common, with axillary, inguinal, and mediastinal lymphadenopathy not infrequent. Approximately $10 \%$ of reported cases have ophthalmological involvement, generally limited to the orbit and eyelids. ${ }^{67}$

Berger and associates ${ }^{\gamma}$ observed keratic precipitates in a young girl during a routine eye examination. The patient also had a raised intraocular pressure which appeared to fluctuate according to the status of her systemic disease. Friendly et al. ${ }^{7}$ described four cases with orbital involvement and ocular complications. One patient developed endophthalmitis necessitating enucleation, and in another patient a subconjunctival mass in the medial central region extending into the orbit was excised.

Our case illustrates that the conjunctiva and nasolacrimal drainage system can also be affected in sinus histiocytosis with massive lymphadenopathy as part of the disease's extranodal involvement. ${ }^{6}$ The chronic dacryocystitis was most probably due to involvement of the nasal mucosa by sinus histiocytosis spreading round the inferior nasolacrimal drainage system, resulting in obstruction. Nasolacrimal tubes improved the chronic dacryocystitis, and the other ocular lesions regressed. Only a long-term follow-up can determine the final outcome of the disease process.

The cause of sinus histiocytosis is obscure. The condition is considered to be a primary immunodeficiency of histiocytes or of infectious aetiology. Sinus histiocytosis should be differentiated from Burkitt's lymphoma and other malignancies as well as from histiocytosis $\mathrm{X}$, which is totally unrelated. The histopathological features of the disease are a result of remodelling of the lymph nodes, which is similar in extranodal sites as well as in the lymph node itself.
Epithelial membrane antigen (EMA) denotes a group of glycoproteins which are present in epithelial cells and appears to act as a marker of proliferation in some epithelial and non-epithelial cells. EMA positivity has been reported in certain types of histiocytic proliferations. ${ }^{910}$ To explore this phenomenon, immunoperoxidase stains for EMA were performed on multiple sections in our case, but failed to reveal significant EMA positivity.

Therapy is not specific. Some cases respond to local excision, systemic immunosuppression, or radiation.

\section{References}

1 Rosai J, Dorfamn RF. Sinus histiocytosis with massive lymphadenopathy: a pseudolymphomatous benign disorder. Analysis of 34 cases. Cancer 1972; 30: 1174-88.

2 Wright DH, Richards DB. Sinus histiocytosis with massive lymphadenopathy (Rosai-Dortman disease): report of a case with widespread nodal and extra nodal dissemination. Histopathology 1981; 6: 697-709.

3 Foucar E, Rosai J, Dortman RF. Sinus histiocytosis with massive lymphadenopathy. Arch Otolaryngol 1978; 104: 687-93.

4 Thawerani H, Sanchez RL, Rosai J, Dorfman RF. The cutaneous manifestations of sinus histiocytosis with massive lymphadenopathy. Arch Dermatol 1978; 114: 191-7.

5 Codling BW, Soni KC. Barry DR. Martin-Walker W. Histiocytosis presenting as swelling of orbit and eyelid. $\mathrm{BrJ}$ Ophthalmol 1972; 56: 517-30.

6 Foucar E, Rosai J, Dorfman RF. The ophthalmologic manifestations of sinus histiocytosis with massive lymphadenopathy. $\mathrm{Am} \mathrm{J}$ Ophthalmol 1979; 87: 354-67.

7 Friendly DS, Font RL, Rao NA. Orbital involvement in sinus histiocytosis. A report of four cases. Arch Ophthalmol 1977; 95: 2006-11.

8 Berger L, Gait J, Allansmith MR. globe involvement in sinus histiocytosis. Am J Ophthalmol 1983; 95: 124-5.

9 Rabkin MS, Kjeldsberg CR. Epithelial membrane antigen stain patterns of istiocytic lesions. Arch Pathol Lab Med 1987; 111 337-8.

10 Karcioglu ZA, Haik BG. EMA stain lesions of the eye and adnexa. American Academy of Ophthalmology meeting, Dallas, 1987.

Accepted for publication 13 July 1987. 